\title{
A Traceable Cancer Model: DNA Damage, Fragile Site-SMGs, Mitotic Slippage, 4n-Genome-Reduction to Fitness-Gained, Initiating, 2n First Cells
}

\author{
Kirsten H. Walen \\ CROMOS, Richmond, CA, USA \\ Email: kwalencromos@gmail.com
}

How to cite this paper: Walen, K.H. (2021) A Traceable Cancer Model: DNA Damage, Fragile Site-SMGs, Mitotic Slippage, 4nGenome-Reduction to Fitness-Gained, Initiating, 2n First Cells. Journal of Cancer Therapy, 12, 365-386.

https://doi.org/10.4236/jct.2021.126033

Received: May 11, 2021

Accepted: June 20, 2021

Published: June 23, 2021

Copyright (อ 2021 by author(s) and Scientific Research Publishing Inc. This work is licensed under the Creative Commons Attribution International License (CC BY 4.0).

http://creativecommons.org/licenses/by/4.0/ (c) (i) Open Access

\begin{abstract}
We have known since 1976 that cancer evolves clonally from one initiated normal human cell, the first cell. Today we see that this fact has been overshadowed from federal funding choice of the mutation theory (MT), which not yet has shown tumorigenesis-initiation in normal human cells. Our suggested, death signaled, stress model from time delayed S-period (replication slowness), causing repair instability from under-replicated lesions in repetitive DNAs, herein has the objective of revealing, significant literature support from a mini-review. We reasoned that early versus late S-period stress would have different outcomes: early the slowness affecting mitotic slippage with diploid re-replication to $4 \mathrm{n}$ cells whereas late-S, with milder stress effect, producing diploid cells. In cancer burden, near-half is diploid, but tetraploid solid tumors have the attention. The initial $4 \mathrm{n}$ cells were special with orderly genomic reductive division to diploid first cells with measurable fitness-gain from hours-reduced total cell cycle time. Experimental data from CoxsakieB3 virus infected normal fibroblasts, reiterated $4 \mathrm{n}$ cell production from deathsignaled recovery-cells with progressive cell-phenotypic changes to polygonal and roundness cell-shapes, indistinguishable from diagnostic/prognostic cancer morphology. The $4 \mathrm{n}$ cells showed a self-inflicted $90^{\circ}$ turn of the $4 \mathrm{n}$ nucleus before division, affecting a perpendicular orientation of the fitness-gained first cells relative to neighboring cells. In an illustrated cell cycle drawing with early and late S-period stress, it became clear that coding genes on borders of repair unstable satellite, repetitive DNA regions, could become mutated. We found these mutations to be tumor SMGs (significantly mutated genes). Evidential material was presented for loss of function genetics driving tumorigenesis to a parasitic lifestyle.
\end{abstract}




\section{Keywords}

S-Period-DDR, 2n-4n- $90^{\circ}$ Nuclear Turn, Cytoskeleton/Cell Polarity

Amitosis, Time-Short Cell Cycle Fitness-Gain, Aneuploidy, Loss-of-Function

Genetics, Parasitic-Tumor Life, Therapy-Possibilities

\section{Introduction}

It is paradoxical that diagnosis and prognosis of cancer occurrence are today done from histology and morphologies when the accepted research focus is overwhelmingly on mutation-cause of the disease. This status quo has mostly been derived from the mind entrenched idea in the mutation theory (MT) that certain mutations SMGs, occurring "spotted" in different tumor types, act as drivers of tumorigenesis (in the literature: driver or cancer mutations) from initiation to malignant metastasis [1] [2] [3]. This belief is based on the mutations being tumorigenesis initiating and selected-for during progression. In this report, this view is challenged from known chromosomal site fragility, chromosomal breakage-prone locations, co-located with repetitive common fragile sites, known to cause genome instability from DNA breakage repair processes [4] [5] [6]. We also refer to a work by one of the "driver" originators [7], which also seriously throws doubt on the interpreted driver capacity of these mutations. The focus on this "gene centric" view is mainly due to "driver genes" being decision-makers of therapy approach in the ongoing tumor personalized treatment, which has shown significant plus/minus variable results [8] [9]. From the existing in vitro models for tumorigenesis, the previously reported special type tetraploidy as originator of tumorigenesis is again the focus in this report [10] [11] [12]. This, because of being the only model with first cells showing moderate fitness-gain, a hallmark requirement in tumori-genesis initiation [13]. Furthermore, none of the other models have shown normal human cell origin, which was evidentially presented for our model from two different normal human cell strains (WI-38 \& L645), signifying, likely in vivo origin in tissue normal cells where cancer originate. One recent investigative program, the New Initiative [14] is especially of concern, regarding useful information for promised therapy with cancer control in a 10-year "moon-shot" even with eradication advocated on TV and radio. The more recent "talks" from this program is risk assessments for cancer origin, IF you-me are carriers of these assumed driver mutations, which "me" today (May/2021) was asked to participate in by blood donation. So far, 7 - 8 years in operation without announced positive results, while bio-companies are competitively in drug-findings against such SMGs, the question is whether this is a wisely, tumorigenic dollar investment from limited research funds. Herein the value of tumorigenesis models are seen firstly, from evidential material showing applicability to normal human cells, so far, none from the Initiative, not even show 
of fitness-gain, supporting the claim of tumor driver capacity. The second most important value of an in vitro model, is that it reveals therapy specific vulnerability, which can serve in a rational way for anti-drug treatment decisions. To this end, several published reports are already pertinent [15] [16] [17]. It is to be remembered that cancer is a deadly disease and not an intriguing biology question.

\section{Primary Normal Human Cell Strains}

Firstly, there is need of awareness to normal human cell strains not being easily cultured for optimal $3 \%-4 \%$ mitosis, and that they are rather proliferative intolerant to "hard" handlings, for example, machine use, centrifuge, vortex in pellet re-suspension etc., and chemicals (wrong medium composition) inducing gross genome changes [18]. Herein, proof of DNA damage from antibody- $\gamma \mathrm{H} 2 \mathrm{AX}$ nuclear/chromosomal foci [19] [20], would have been highly desirable for the demonstration of death signals, inducing DNA double strand breaks (DSBs). There are neither procedural nor kits available for this test in normal cells as it is for cancer cell lines. Herein, this prevented show of virus induced cell-killing, being associated with genomic damage, which is a missing evidence for the recovery growths, being initiated from successive genomic damage occurrences. As a result the need is for repeat experiments from for example, cancer-drug induction of DNA damage, which has the potential for molecular further analyses perhaps for vaccine exploration (below), since such regrowth patterns, would not be destroyed from virus presence.

\section{Previous Glutamine-Deficiency Stressed Induced Cellular Responses}

Two studies have shown spontaneous occurrence of special $4 \mathrm{n}$ diplochromosomal cells with sudden origin from near-senescence normal cells, characteristically with attrition, short uncapped telomeres (i.e., genomic damage) [21] [22]. Both concluded that this DNA damage was the cause of these special tetraploid cells, with structurally abnormal chromosomes showing 4 chromatids instead of normal 2 chromatids. We induced these changes by transient absence of amino acid glutamine in the growth medium of young normal fibroblast cells [23] [24] [25]. This particular amino acid had in metabolic studies, been found to significantly contribute nitrogen and carbon to metabolic processes, and when absent, DNA damage was observed in cells [26] [27]. On the cell-culture level tetra- and octoploid cells were responses when glutamine was deficient in the growth medium [27], which interpretively indicated a DNA damage response with repair from recombination between the multi-chromatids within one chromosome. Tetraploidy and higher levels are well known from tumor progression stage [28] [29]. This mitotic recombination feature between four chromatids of one chromosome was clearly demonstrated from tritiated thymidine autoradiography labeling [30]. This unique happening in diplochromosomal cells was also discovered 
to be ongoing in the cancer prototype model, hereditary Bloom's syndrome [31] [32], in which the DNA damage was from a mutated gene for RecQ-helicase enzyme. A series of glutamine-deficiency experiments revealed some extraordinary features of the $4 \mathrm{n} / 8 \mathrm{C}$ division system: 1) Genome reductive division to diploid first cells, expressing fitness-gain. In animals with parthenogenesis, the gamete division was also from "-lack (of) pairing of chromosomes", approaching "a mitotic division-" [33]. 2) Metaphase rosette-figures showed whole genomic separations of $4 n / 8 C$ to $4 n / 4 C$, which divided to $2 n / 4 C$ or $2 n / 2 C$ cells, which expressed extended fitness-gained proliferation to a replicative-like senescence [21] [22]. But most importantly the $2 \mathrm{n}$ diploid cells (first cells) showed further genome segregations to near-haploid genomes, which are occurrences in childhood leukemia and also in small cell lung cancer [11] [14] [17] [34]. The most peculiar aspect of the $4 \mathrm{n}$ division system was perpendicular to the cytoskeleton mitotic figures, which liberated such cells from contact inhibition and gave movability to the resulting offspring, the first cells which were in a skewed position relative to the surrounding normal cells [15]. Gain of movability in migrating cells has been detailed with markers, perhaps therapy relevant [35]. This remarkable tetraploid division system was named GR4n-SDS (genome reductive $4 \mathrm{n}$ skewed division system) to distinguish it from other types of tetraploidy (i.e. 92 chromosome $4 \mathrm{n}$ cells). All in all, the $4 n$-cell unique birth process and division system constitute an in vitro traceable model for First Cell origin with potential for Cancer disease. Recently, First Cell investigative research was suggested to be a needed cancerous change in a book by Azra Raza [36], who came to this conclusion from 35 year-long oncology experience, seeing hit and miss-type therapy results and, how patients, painfully reacted to the medicines with horrible side effects, but dying anyhow, inch by inch.

\subsection{The Skewed Division Phenotype}

The above mentioned perpendicularity change involved a $90^{\circ}$ turn of the $4 \mathrm{n}$ nucleus before division in this same polarity changed condition, which led to withdrawal of the old cyto-skeleton with result of destruction of cell-to-cell adherence proteins (i.e., E-cadherin and $\beta$-catenin, cancer well known), giving movable freedom of the first cells. A further consequence was that these cells were born in a perpendicular orientation to the surrounding normal cells, and that they had to rebuild a new cytoskeleton, changing cell polarity and cell shape (wa). In the literature a perpendicular whole cell change is ascribed to gain of embryological "epithelial-mesenchymal transition" process (EMT or MET) [37] with outcome of destroyed inter-cellular adherence proteins for movability, but certainly not with link to a rebuilding of the cytoskeleton and cell polarity and cell shape changes. Cell polarity changes have been suggested to be the "gate" to tumorigenesis [38]. But back to EMT/MET, a report on ovarian cancer cells in metas-tasis showed note, $4 \mathrm{n}$ dividing cells in a perpendicular orientation relative to the cytoskeleton ("cytoskeleton skewed tetraploid"), which released migratory 
cells with colonizing ability in other body organs [39], which throws serious doubt on the EMT hypothesis. Remarkably, this same type of perpendicularity of nuclear divisions was described from the extent unicellular organism Aulachantha and a bacteria [40] [41] which also was a feature in genomic doubling recombination repair, and furthermore, showed segregation of whole genomes. Evidential material for mammalian genome conservation of these archaic (pre-mitotic/meiotic) nuclear/division traits comes from nutrition deficit Drosophila cells, claiming amitosis in the absence of a normal spindle apparatus [42]. This occurrence and our own observations of amitotic abnormalities in fitness-gained first cell proliferative activity with multicellular growth, suggested that DNA damage exposed cells, responded with awakening of evolutionary conserved, archaic division traits, pre-mitosis/-meiosis evolutionary division trait. This happening would put amitotic division traits into human cells with mitosis, leading to questions of adaptation or apoptosis occurrences? It was concluded from the abnormal whole complement segregations without normal anaphase behavior that an adaptation had occurred, which was called amitotic-mitosis.

\subsection{In Vivo Sought Evidence of Amitotic-Mitosis}

In oral aggressive cancer the cytoskeleton showed "defects" [43], and in colon crypt with APC mutated gene, the resultant proliferative growth was found in measured $90^{\circ}$ turn relative to the basal cell membrane [44] [45] which proceeded to the cancerous cell phenotype from tetraploid aneuploidy. The foregoing precancer phase also showed accumulation of $4 \mathrm{n}$, a feature in two other pre-cancers, ulcerative-colitis and Barrett's esophagus [46] [47]. In addition the latter report showed that cytometric isolated $4 \mathrm{n}$ cells became cell culture "enriched" via a $2 \mathrm{n}$ cycling phase $(4 n>2 n>4 n>2 n>$-etc.) $)$ expressed by one tall peak for $4 n$ cells and a new smaller peak with measured $2 n$ ploidy cells. This latter remarkable observation in the absence of $4 \mathrm{n}$, aneuploid divisions, demonstrated inherited capability of the diploid cells to instigate $4 \mathrm{n}$ cells, genome reductive behavior. Recently in soft tissue sarcoma cell lines, it was shown that there were over-expression of some mitotic genes (the CINSARC phenotype) by highly mobile and invasive $4 \mathrm{n}$ cells, which did not express "proliferative advantage", compared to the diploid cells present [48]. The authors theorized that the cytoskeleton was miss-behaving from the mitotic proteins, and developed a screen for drugs with anti-mitotic and anti-cytoskeleton effects, and thereby discovered that inhibition of "several mitotic kinases", dramatically, impaired the "invasive and migratory properties" of the $4 \mathrm{n}$ cells. These in vivo "special" $4 \mathrm{n}$ cell behaviors, were no different from the observed behaviors of the in vitro GR4n-SDS cells, suggested to be a traceable model system in tumorigenesis. Notably, the $4 n$ in vivo cells demonstrated therapy vulnerability with cancerous effect. These developments appear tumorigenesis more likely than the tumor driver idea (below), with the above therapeutic promise likely enhanced from molecular landscapes of the special $4 \mathrm{n}$ and fitness gained $2 \mathrm{n}$ cells. 


\section{Experimental Results and Discussion}

In a most recent article we reported on recovery growth from an RNA virus (Coxakie-B3), highly efficient in cell killing, which in virologist judgment was a $100 \%$ cell-death, described as 4+CPE (cytopathic effect) [12] [49]. The last reference has photographic illustrations of the remarkable virus induced progressive histological and morphological cell-shape changes from normal mono-layered fibroblasts to multilayered striated cells to polygonal and last to roundness type cells. These in vitro changes were indistinguishable from histology and morphology used today in diagnosis and prognosis, which is a landmark achievement from an in vitro model of tumorigenesis, never before observed. These recovery growths after virus induced $4+\mathrm{CPE}$, agrees with the recent discussions [50] of "sick cell" recuperation with regrowth, giving rise to relapse tumors. These relapse tumors were found to be from polyploid giant cells, having formed multinuclear cells, known today as; Polyploid Giant Cancer Cells (PGCC) which can "sprout" lower ploidy cells, giving rise to relapsed tumors [28] [29] [48] [51]-[56]. "Sprouting" meaning bud-ding of karyoplasts, a cell membrane surrounded nucleus in need of self-synthesized cytoplasm, which was much earlier found to be an innate trait of normal cell polyploidy [15] [57] [58] [59] [60] [61]. In addition the PGCC studies revealed that the budded growth showed mutational changes different from that in the mother cell, which conferred tumorrelapse therapy resistance [54] [55]. Interestingly, the human polyploid cell budding was similarly mechanistic shown from an ameba, demonstrating the atavistic genetic conservation in our genomes [62].

But back to the virus induced different cell shape regrowth, on chamber slide growth with in situ analyses of the beginnings of these various cell patterns, the mitotic figures, specifically did not fit into the confines of a spindle apparatus, which normally guides mitotic process through ana-phase to centrosome MTOCs (microtubule organizing centers) at the opposite polar regions. This discrepancy asks many therapy related question, and also if there is evidential material from cancer cell lines or biopsies for occurrence of these mitotic abnormalities, which remarkably, were similarly, microscopy-described from cancer cells themselves, two centuries ago [63]. Our photography of these abnormalities were presented on composite plates over the last decade [10] [11] [15]-[25]. The noted increase in condensations of the "anaphase/telophase" (amitotic-mitoses) genomes in the progression from fibroblast-control cells to the roundness-type cell pattern, has been called compaction in cancer cells, which was seen as a defense mechanism against environmental "unforeseen" genome damage occurrence [64]. The extreme of "mitotic" abnormality is multipolar division (MP), which has exclusive occurrence in cancer cells [31]. These MPs from multi MTOC-centrosomes with generated spindle apparatuses, showed in one cancer-cell study that some of these MTOCs lacked centrosome-centrioles [41]. We ask if there is structural deviations from normal "umbrella-shaped" anaphase figures in single mitosis of cancer cells. In the mean-time there is sufficient evidential material from the 
earlier and herein observed division figures' lack of normal mitotic spindle apparatus to warrant an acceptance of amitotic-mitosis in divisions of polyploid multi-chromatid genomes with genome reductive behavior and, in cancer cells. A model of tumorigenesis is only Cancer useful when it provides specificity of a trait, a phenotype, with probability of being therapy vulnerable. Today the emphasis appears to be on the biological intricacies of the model itself, often with a last sentence proclaiming therapy importance of the whole model system, which is completely un-useful. Cancer is a horrible disease, and a therapy-centered goal, is an only worthwhile property of any investigative model system, unveiling/-recognizing, structural or functional traits with action in the various ways the cancerous geno-phenotype is attained. There are several such data acquisition systems with genome sequencing being one, another is morphology of phenotypes in the stepwise cancer evolutionary process, one example being the morphologies of the virus-regrowth. Molecular data revealing gain of function mutations has high probability of being drug therapy targetable, which might stop cancer cell proliferation. The cancer diagnostic-alike morphologies of the different regrowth are tumorigenesis phenotypes, which should be assessed for drug sensitivity. Whether these cell-killing regrowths can inform on mechanism(s) for occurrence of relapse tumor is also a worthy consideration. More than enough questions based on real tumorigenesis relevant data for some Ph.D. programs, hopefully offered with grant funding for young open minds, not cluttered with chemical approach to the cancerous solution. Will this happen? Not likely, because of the mind-entrenched acceptance of the tumor driver mutation theory [1]. The possibility of vaccine investigation into cell-based, antigen-antibody response from the GR4n-SDS cells or from their derived First Cells, is becoming a real possibility for such investigative inquiry (see below).

\subsection{Proof of Fitness-Gain}

Left is evidential proof for the first cells' expressed "proliferative advantage", the hallmark for tumorigenesis initiation from normal cells (H/WREFF). This was earlier done from glutamine deficiency experiment from proliferative first-cells [65]. Such cells were seeded at $7-800,000$ cells into each T-25 flasks, with similar seeding from normal optimum, proliferating normal cells. Hemocytometer readings of growths at 3 days, showed normal cell values 1.7 and $2.2 \times 10^{6}$ and experimental values, 3.4 and $3.7 \times 10^{6}$ cells in two different readings each, which is low, and likely only expresses as moderate proliferation difference from normal cells. These initial measurements showed 5 million more cells in fitness-gain cultures than in the control cultures with the notable, cancer-associated characteristic of being multilayered growth. To this important in vitro cancer-associated observation, there had earlier been an observation of special $4 \mathrm{n}$ cell derived 3-D tumor-like spheres with polygonal cell shape changes, floating free in the liquid growth medium, or being attached to the cultural surface [66]. These photographic illustrated spheres/balls of cells, revealed in 5 - 6 week old senes- 
cent cultures, can be likened to in vivo senescence, colon adenoma and breast DCIS (ductal carcinoma in situ) pre-cancers, having "risk" of oncogenic transformation. Furthermore, both in vitro and in vivo "oncogenic" transfor-mations were preceded by senescence-associated telomere DNA damage from natural, time-dependent attritions, abundantly earlier shown to cause genomic instability, notably, breakage-fusion-bridge (B-F-B) cycles, well known in cancers [67]. From this latter development a pre-dicttion is that exposure of multilayered first cell growth to a cell killing agent (DNA damage), the recovery growth would show cell shape change, different from that in the multi-layered growth (fibroblastic-like) and, the growth might be 3-D-like under proper cultural con-ditions (soft agar?). The virus work above, undeniably demonstrated that successive death signaled cells responded with regrowth, which histological and morphological was cancer-alike to diagnostic and prognostic criteria used in cancer-pathology today. This never before obtained in vitro happening, cries loudly for further investigations. Don't let this in vitro landmark occur-rence from GR4nSDS derived first cells, be pushed "under the rug", cancer is a deadly, patienthorrible disease, and not an intriguing biological issue, as said above. And, also, don't let big time profit [8] [9] [12] hinder you from the likely disclosure of therapy relevant, novel information from molecular sequencing data of special $4 n$ and 2n fitness-gained cells.

\subsection{Mitotic Slippage Process or not in Genome Damage Exposed S-Periods}

In Figure 1 three different cell cycle circles from mitosis to mitosis are shown: (A) - normal cell cycling, (B) - stress associated cycling, and (C) - suggestions of endoreplication models [68] [69] [70]. Left-out is so-called endomitosis in which the replicated cells goes into mitosis, but performs only anaphase A not B, followed by re-enter into S-period, which has been adopted from megakaryocyte cycles [71]. This particular polyploidization mechanism have been discussed in two recent reports [72] [73]. Herein the slippage process in cause of tetraploid cells is uniformly considered, mainly because of evidential documented deteriorated mitotic program, Cyclin B and kinase Cdk-1 destruction [74]. As mentioned mitotic slippage process is also a consequence from normal telomere attrition at senescence, which was associated with appearance of 46, 4-chroma-tid chromosomes [21] [22] [23] [24] [25]. The shortened uncapped telomeres (DNA damaged signaling) much earlier were shown to be associated with breakage-fusion-bridge (B-F-B) cycle, giving rise to dicentric chromosomes, which is a cancer occurrence [75].

\subsection{Cell Cycle Checkpoint Controls and Their By-Pass}

Back to the normally depicted cell cycle (Figure 1(A)). In this cycle from one mitosis to the next, checkpoint controls guide against abnormalities, which are situated at the borders of "phase" changes. For example, the checkpoints at 


\section{A. NORMAL CELL CYCLE \\ M-Mitosis, $1-2-1 / 2$ hours \\ G1-phase, 8 - 10 hours \\ S-period, 8- 10 hours \\ G2-phase, 2-3 hours}

Black box, late replicating satellite DNAs

\section{B. REPLICATION STRESSED CELL}

\section{CYCLE}

$\mathrm{X}$ - early S-period stress, Y - late S-period stress

Wiggled X-line: time prolonged $\mathrm{S}$, deletion lesions in satellite DNAs, abnormal G2, mitotic slippage, short G1-phase, chromatin $2 n$ cells bypass of $\mathrm{G} 1$ checkpoint, into $\mathrm{S}$, replication to $4 \mathrm{n}$ cells, mitotic-meiosis to $2 \mathrm{n} / 4 \mathrm{C}$ karyotype normal cells with fitnessgain (4n-SDS cells to first cells, Walen 2019).

Wiggled Y-line: short stress-time, lesions in satellite DNAs questionable, G2 normal, $2 n / 4 C$ cells in $M$ dividing to two $2 n / 2 C$ daughters, normal cell fitness.

\section{ENDOREPLICATION CYCLES}

The partial circles $a$ and $b$ demonstrates endocycles bypassing S-period and mitosis (Edg/OrrWeaver, 2001). The small circles C within the S-period show multiple DNA synthetic cycles from different origins, with indistinct DNA content (Lee et al, 2009).

The third model is a revolving $\mathrm{G}-\mathrm{S}$ circle, in which each diploid genome is a DNA complete unit (Fox et al, 2013).
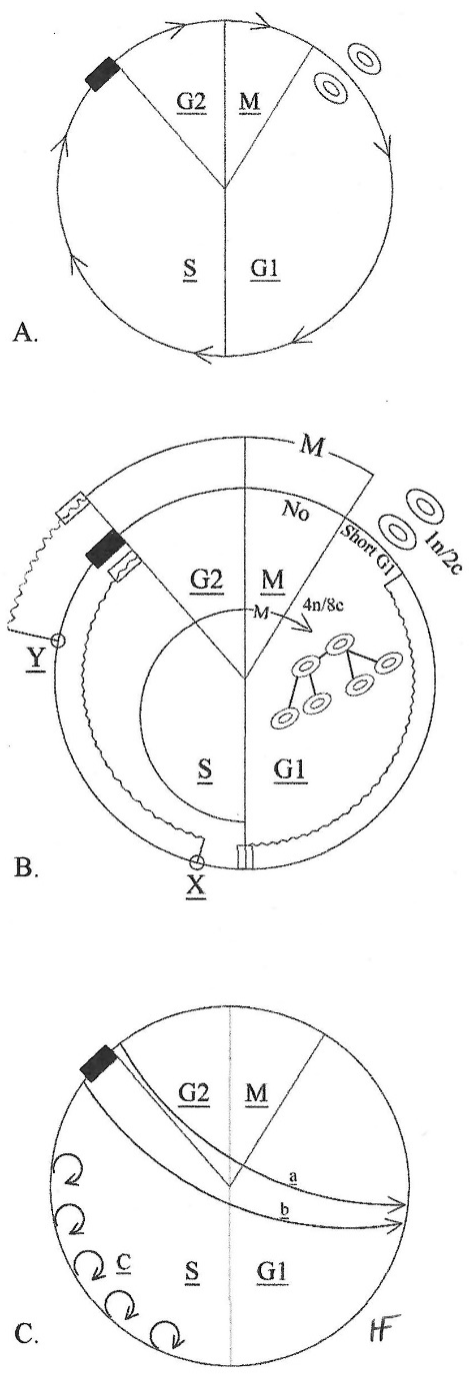

Figure 1. Illustrated cell cycles: (A) normal cell cycle with time durations of the different phases, (B) replication stress early, X-line and late, Y-line in S-period, (C) endoreplication models. The X-line is shown stopped at the G2 border, because it is not known how far it proceeds with chromatin condensation, before stopped at the G1 border from mitotic slippage process.

G2/M and at G1/S have received a lot of attention, which normal cells activate regularly with apoptotic/necrotic discard of miss-behaving cells. But stress on the replication S-period (Figure 1(B), wavy X\&Y lines) with cause of slowed/ stalled replication forks, have shown completions of the cell cycle without activation of these check-point controls [76]. For the X-line with early S-period stress (likely DNA damage) this would lead to chromatin condensing G2 cells, being at the border of G1-phase, because of skip of mitosis, but unable to continue cell cycling from chromatin status in disagreement with that normally expected from telophase de-condensation (unpub). Our early work showed that the eventual continued cell cycling with $2 \mathrm{n}$ re-replication in second S-period gave rise to $4 \mathrm{n}$ cells with recombination chiasma between the 4-chromatids of 
diplochromosomes, a tritiated thymidine incorporation demonstration [30]. This work was corroborated one year later by a textbook "perfect picture" [31]

[77] with excessive chiasma counts in Crohn's syndrome with 46 numbered 4-chromatid chromosomes [31].

\subsection{Prolonged Mitotic Arrest from Spindle Poison, Giving Rise to Coding Gene Mutations}

In an article from the Pellman laboratory [78], abnormal mitosis was linked to gain of DNA damage, which earlier had been shown to involve tetraploidization from spindle poison treated cells [79]. They presented data showing mitotic poison associated "prolonged mitosis"-, giving rise to $4 \mathrm{n}$ cells with mild mutational changes, a little later confirmed by different cancer-drug inductions. But the question of why non-DNA-damaging spindle poison produced mutations became an unsolved issue. However, considering that metaphase arrested diploid cells spend various times arrested (hours 6 - 16, depending on experiment) before there was observed "slip-back" into the cell cycle of the $2 \mathrm{n}$ cells with tetraploid cell-result from a second S-period. There would then have been various S-period stress periods with slowed-down replication cycles, affecting mutational changes in late replicating satellite DNAs. The consequent repair processes would be a source for genomic instability [10] [11]. These observations were verified from repair DNA foci, $\gamma$-H2AX, notably, in cancer cell lines [19] [20]. An explanation for this spindle poison-associated mutational change was offered by the suggestion that the p53 gene with the ability to "sense" mitotic time duration had become dysfunctional and had let diploid poison arrested cells slip through the G1/S checkpoint [80], and there is where it stands today. In general, the various types of producing polyploid cells are not considered for associated mutational happenings. But perhaps worse is the still use of spindle poisons in cancer treatment, which from above is a risky procedure for induction of relapse tumors with mutational changes.

\subsection{A Closer Look at Mutational Happenings in Late Replicating DNAs}

Slowed-down S-periods, cell cycle compensated by incomplete replication of late replicating DNAs, as mentioned the non-coding satellite DNAs from nucleotide repetitive regions, which has four different chromosomal locations, the fragile sites, microsatellites, centromere and telomere regions [4] [5] [6] [19]. Repair of such lesions were early shown to involve multiple trials "within confined nucleotide regions" [81]. These trials were more recently shown by large RNA transcripts to "unite" fragile site repair locus with coding gene mutational happening located on the "border" of such unstable "dark DNA" repair [82]. Supporting is an earlier article also with focus on time prolonged cell cycle, "DNA replication stress underlies DNA, DSB (double strand breaks) formations in human precancerous lesions" [20]. In Figure 1, the Y line depicts late S-period stress, which is likely to produce less S-period, time disturbance with milder dark DNA muta- 
tional types ( $C>G$, etc. types) which would not give rise to mitotic slippage process. Thus such cells would divide normally to proliferative diploid $2 \mathrm{n} / 2 \mathrm{C}$ cells, likely not expressing fitness-gain with proliferative rate no different from normal cells. These diploid cells (First Cells) from late S-period stress we propose to be the origin of diploid cancers (48\% of total tumor burden), which are "lazy proliferative cells" with decades to cancer phenotype [83].

The Glover laboratory, has spent a life time on experimental inductions on mutational events in dark-DNA, especially on how it can affect repair instability in common fragile sites (over 100 genomic distributed). They early-on showed that these "fragile sites" (FRA) were co-located with natural chromosomal structural more or less, weak break sites, which adds to the observed repair instability. Lately they used mild X-ray induced genome damage in normal cells, and observed molecular copy number alteration/variability (CNA/V), which has mutational inactivation affect. This tumorigenesis increasing finding is cancer-visually observed from frequent HSRs and DMs, in different types of cancers, but generally, lacking acceptance of gene-inactivation properties [10] [11]. Lastly, cancer therapy stands to gain important information from knowledge of how giant polyploid cells segregate into multinuclear cells, the PGCC [84] [85] [86] [87] [88], which also should be considered of being therapy resistant from surrounded extracellular matrix (See Wikipedia). In the past this latter hiding mechanism from cancer killing drugs had attention, which likely can be brought forward from the more advanced technology, which like-wise extended to the nuclear/cell budding process [21] [22] [23] [24] [25] could stop the PGCC from having tumor-regenerating capacity. In other words it is not enough to show/ suggest how these dangerous cells are generated, unless it is informative on today's possible ways of therapy, remember it is a disease, not a mind "pleasing" biological problem.

\subsection{Evidences for So-Called Tumor Driver Mutations to Be from Bad Chromosomal Locations}

The early mentioned association between satellite DNA repair instability and mutations in bordering located coding genes [4] [5] [6], evoked the question of whether the most frequently mutated genes among the SMGs would be chromosomally located in such "bad" chromosomal locations. For that inquiry the genes, TP53, Rb, CDKN2A, APC, RAS, MYC-N, MYC-C, MET and FHIT were found with the respective locations: 17p11.2, 13q13, 9p21.2, 5q22, 11p15, 2p24, 8q24, 7q21-31, 3p14.2 which surprisingly were all chromosomal sites near-by common fragile sites (FRAs). This was determined from G-banded genomes, which from Giemsa stain produce a white and black striped chromosomal reproducible pattern. Early-on these patterns were shown to achieve a most remarkable happening that of coding genes in thick and thin, black bands, whereas the white bands were almost devoid of such important genes (Therm [31]. In the summarized articles on common fragile sites [4] [5] more than 100 fragile sites are mapped to a haploid chromosomal genome with locations, which can be 
used to grossly assess where a gene is located, in dark bands or on their edges to white bands. Improved resolution can be achieved from ISCN Nomenclature [89], which shows G-banding of much longer chromosomes than generally done for karyotyping. For example, the CDKN2A gene (p16ink4a) is in a dark band on regular karyotype chromosomes, which became split into two dark bands by a white narrow band with the gene' location 9p21.2, clearly seen on extended length chromosomes. Interestingly, p53 mutation being the most frequently mutated gene in tumors is located on chromosome $\# 17 \mathrm{p}$-arm on the border to centric heterochromatin, which give this gene several ways for mutational occur-rence: 1) from natural mutation rate occurrence, 2) from repair instability of either an under-replicated lesion or a natural replication error in the centric repetitive DNA, and 3) simple breakage with p-arm, p53-gene loss. Below is another list of both LOHs and single nucleotide mutational changes with fragile site relationships from various cancer-types (prostate, skin, lung) including a 1996 report from LOHs in breast and prostate cancers [90].

\begin{tabular}{|c|c|c|}
\hline$\underline{\text { Single mutations \& LOH regions }}$ & $\underline{\text { Fragile sites }}$ & \\
\hline $1 \mathrm{p} 13.3$ & \multicolumn{2}{|c|}{ Centric white band-Gene symbol KCND3-FRA1p13.3 } \\
\hline $3 \mathrm{p} 24$ & & FRA3A-p24 \\
\hline $5 q 35.1$ & & FRA5-q31 \\
\hline $5 q 35.3$ & & FRA5q-25.3 \\
\hline $6 \mathrm{q} 23-27$ & & RA6E-q26-8p2.1 \\
\hline $8 \mathrm{p} 22.1-24$ & & RA8B-p22-9q21 \\
\hline $8 \mathrm{p} 22.1-\mathrm{q} 24.12$ & LOH region uniparental disomy-FRA sites $8 \mathrm{H}$ & B-p22 \& 8B-p12 \\
\hline 9p12-p34 & FRA9D-p22.1 \& Eq32-31-Inclusi & ive of CDKN2A \\
\hline $10 \mathrm{q} 24-26$ & FRA10E-q25.2 \& FR & RA10F-q24-26.3 \\
\hline $11 \mathrm{p} 15.5$ & & FRA11C-p15.1 \\
\hline $11 \mathrm{q} 31-\mathrm{q} 24.2$ & FRA11F-q14.2-q24.2 \& & FRA11F-q14.2 \\
\hline $13 q 13$ & & FRA13A-q13 \\
\hline $15 q 14-q 23$ & & FRA15A-q22.1 \\
\hline $16 \mathrm{p}-$ & Loss of p-arm (centro & omere breakage) \\
\hline $17 \mathrm{p} 13.1$ & White band $\mathrm{n}$ & ear tip of $p$-arm \\
\hline $17 \mathrm{p} 11.2$ & Location o & of TP53 17p11.2 \\
\hline
\end{tabular}

Some of these $\mathrm{LOH}$ loci were reported in more than one tumor similar to LOHs in breast hyper-plasia, discussed earlier (Wa 16, 17, 56). And interestingly, chromosome arms, 10p, 12p, 16p, 17p, 18p, 19p\&q, 20q, 21q have no reported fragile sites in the 2007 map (D/G (4)), which rumors says has been renewed with more locations. It is a pity that the involved listed genes for these identified "bad" locations were not identified, but in the next instalment from melanoma cancer the list will include location, names of genes and their functions (unpub). The most important disclosure is that most of the LOHs were from deficiencies of nucleotides in heterozygous conditions, which explains genome instability and gene inactivation from $\mathrm{CNA} / \mathrm{V}$ and their gross expressions HSRs \& DMs (homogeneously staining regions and double minutes), frequently observed in cancer evolution. To this source for gene inactivation happenings there is also 
the fact that LOHs often express haplo-insufficiency or UPD (uniparental disomy), which all support our contention of loss of genetic function (gene inactivation) being a neutral/passive tumorigenesis evolutionary route to the mature cancer pheno-genotype. But from the list of LOHs in fragile sites the conclusion is that SMGs are not tumor selected-for, but are conse-quence from bad chromosomal locations near repair-unstable late replicating repetitive DNAs (dark $D N A$ ). This statement was convincingly shown to be true for the FHIT gene [4] [91] [92] [93]. A therapy relevant question in regard to these happenings, would likely focus on prevention of the dark-DNA repair processes [94], an approach which has already shown therapy success from new approved drug therapies. But in all of this conventional therapy works, there is a growing shift into algorithmic modeling of tumorigenic events, giving predictions of therapy vulnerability cancer mutational targets. The latest such algorithm is against key transcription factors in indivi-dualized, patient's tumor [95]. But interestingly, the inventor (A. Califano) of this algorithmic approach in the commentary article says: "Theres's say 1000 genes that are recurrently mutated across all tumors that may drive cancer" (our marking). These transcription regulators affects complicated interacting gene network-pathways controlled by genes being on or off, which is presented in a diagram of how a single drug targeting a master regulator, would stop the cancerous proliferative process. Our question is whether this algorithmic model would be therapy efficacy affected by tumor driver mutations not being selected-for, and giving hit and miss therapy results? But sadly, also in this model system as in other models, personal money gain is anticipated in the end of patient exploratory investigations, by the now familiar prior arrangement of for-profit (commercial) companies [8] [9] [12] [96]. An earlier commentator article told of CRISPR editing technology in exploratory work using volunteering deadly cancer-ill patients, which without demonstrated immediate side effects was considered a success with further larger trials being planned, the dying of the patients anyhow, apparently meant nothing. Explorative studies on the back of dying patients is neither ethical nor humane, even though papers for agreements were signed. Such desperate people should have high-priced counseling for risk and benefit. Where is that budget coming from? It is not only paradoxical, but plain sickening that arrangement for anticipated personal profit by sale of the used CRISPR methodology, already was arranged by establishment of a new commercial company [96]. When will we learn that "cancer for profit" decided back in the $1980^{\text {th }}$, has devastating, cancer-negative effect. The greedy human mind [8] [9] although, competitive stimulating for new innovative ideas, it also adds to the cancer, financial industrial Goliath [12], untouchable, too big to fail. Nowhere in its existence would eradication of cancer be a desirable goal, and why fix something not yet broken? No wonder there is a rumor among scientists that cancer will be made into a liveable disease from a pill. Thus, the present high probability of cell-based immune competence for antibody response from the GR4n-SDS or their fitness derived First Cells with significant in vivo support [31] [39] [40] [41] [42] [43] [48] for vaccine explorations, will like- 
ly, never be a serious, open undertaking. The hope is that a commercial company decides to become much richer. But best is that a non-for profit organization becomes established for "out of the frame-type" cancer investigative data with offerings of further investigative, funded programs. This idea, especially directed to offerings of Ph.D. programs, exciting to the young, open clean mind, very likely can be a philanthropy giving, reaching the whole world (unpb.). However, only possible if the Will, is there.

\section{Conclusion}

The conclusions herein are based not only on present data, but on a sequel of progressively attained experimental evidential data from note, two primary normal human cell strains. From this series of publications it was concluded that a special type of tetraploidy (GR4n-SDS cells) showing 4-chromatid chromosomes (diplochromosomes) with demonstrated ability to divide genome reductive to diploid first cells showing measurable fitness-gain, were characteristics required for tumorigenesis initiation. The measured fitness-gain was concluded to be from time-reduced cell cycle. This suggested tractable model system in its further proliferative activity, gained highly likely tumorigenesis applicability from growth character-ristics only known from cancerous development, and therefore, was concluded to be informative for drug-therapy explorations. An example of cancer applicability was regrowth of cells exposed to either nutrition deficit or to virus killing, showing different cell morphology growth patterns, indistinguishable from those used today in diagnostic and prognostic decisions. From cell division studies of the origins of these remarkable morphology changes, it was concluded that these divisions were from an adaptation between amitosis and mitosis, amitotic-mitosis, cancer literature and unicellular organismal supported. The potential therapeutic exploration use of this model system was further shown to get the most beneficial information from drug targeting of a self-inflicted $90^{\circ}$ turn of the $4 \mathrm{n}$ division system. In cell cycle illustrations the model system was outlined from early S-period stress, going through mitotic slippage process to special tetraploid cells with ability to divide to the fitness gained, diploid First Cells. In contrast late S-period stress was depicted to give rise to non-fitnessgained new type of First Cells, but also being diploid proliferating. It was concluded that these First Cells were likely candidates for initiation of Diploid tumorigenesis, $48 \%$ of total cancer burden. Both types of cell proliferations were however, expected to show gained mutational changes from being close to unstable repair of under-replicated lesions in satellite, late replicating DNAs. Such DSB lesions often being deficiencies, impossible to repair back to normalcy, were literature shown to repair-affect mutations in near-by located coding genes, herein strengthened by SMGs and other mutations being positioned on borders of fragile site unstable DNA repair processes. As a consequence a "bad" chromosomal location was concluded to be the reason for the significantly mutated genes, which invalidated the concept of these mutations being selected for. Not meaning that they don't have tumorigenesis significance, but which ones? The 
immediate effect from this evidential shown mutational occurrence is that the ongoing individualized therapy, is on uncertain ground from being based on, the mutations having tumor driver capacity, a fall-out that should be immediately corrected.

\section{Acknowledgements}

I am very grateful to Kathleen Olival for excellent computer help.

\section{Conflicts of Interest}

The author declares no conflicts of interest regarding the publication of this paper.

\section{References}

[1] Stratton, M.R., Campbell, P.J. and Futreal, P.A. (2009) The Cancer Genome. Nature, 458, 719-724. https://doi.org/10.1038/nature07943

[2] Wood, L.D., Parsons, D.W., Jones, S., Lin, J., Sjoblom, T., Leary, R.J., et al. (2007) The Genomic Landscapes of Human Breast and Colorectal Cancer. Science, 318, 1108-1113. https://doi.org/10.1126/science. 1145720

[3] Bozic, I., Antal, T., Ohtsuki, H., Carter, H., Kim, D., Chen, S., Karchin, R., et al. (2010) Accumulation of Driver and Passenger Mutations during Tumor Progression. Proceedings of the National Academy of Sciences of the United States of America, 107, 18545-18550. https://doi.org/10.1073/pnas.1010978107

[4] Durkin, S.G. and Glover, T.W. (2007) Chromosome Fragile Sites. Annual Review of Genetics, 41, 169-192. https://doi.org/10.1146/annurev.genet.41.042007.165900

[5] Artl, M.F., Wilson, T.E. and Glover, T.W. (2009) Replication Stress and Mechanism of CNV Formation. Current Opinion in Genetics \& Development, 22, 204-210. https://doi.org/10.1016/j.gde.2012.01.009

[6] Artl, M.F., Rajendran, S., Birkeland, S.R., Wilson, T.E. and Glover, T.W. (2014) Copy Number Variants Are Produced in Response to Low-Dose Radiation in Cultured Cells. Environmental and Molecular Mutagenesis, 85, 103-113. https://doi.org/10.1002/em.21840

[7] Tokheim, C.J., Papadopoulis, N., Kinzler, K.W., Vogelstein, B. and Karchin, R. (2016) Evaluating the Evaluation of Cancer Driver Genes. Proceedings of the National Academy of Sciences of the United States of America, 113, 14330-14335. https://doi.org/10.1073/pnas.1616440113

[8] Kelty, P.N. (2018) The Cancer Immunotherapy Revolution. Science, 359, 1345-1374. https://doi.org/10.1126/science.359.6382.1344

[9] Mueller, K.L. (2015) Realizing the Promise. Science, 348, 54-56. https://doi.org/10.1126/science.348.6230.54

[10] Walen, H.K. (2018) Genomic Instability in Cancer I: DNA-Repair Triggering Primitive Hereditary 4n-Skewed, Amitotic Division-System, the Culprit in EMT/MET/ Metaplasia Cancer Concepts. Journal of Cancer Therapy, 9, 974-997. https://doi.org/10.4236/jct.2018.912081

[11] Walen, H.K. (2019) Genomic Instability in Cancer II: 4N-Skewed (90) Reductive Division via Fragile Sites to Fitness Increase for Solid and Hematological Cancer Beginnings. Journal of Cancer Therapy, 10, 537-564. https://doi.org/10.4236/jct.2019.107045 
[12] Walen, K.H. (2020) Near-Dead Cells to Special Tetraploidy to First Cells to Cancer Diagnostic Morphology: Unlikely Therapy-Gain from For-Profit Industrial Goliath. Journal of Cancer Therapy, 11, 410-432. https://doi.org/10.4236/jct.2020.117036

[13] Weaver, B.A.A. and Cleveland, D.W. (2009) The Role of Aneuploidy in Promoting and Suppressing Tumors. Journal of Cell Biology, 185, 935-937.

https://doi.org/10.1083/jcb.200905098

[14] Collins, F.S. and Varmus, H. (2015) A New Initiative on Precision Medicine. New England Journal of Medicine, 372, 793-798. https://doi.org/10.1056/NEJMp1500523

[15] Walen, K.H. (2012) Genome Reversion Process of Endopolyploidy Confers Chromosome Instability on the Descendent Diploid Cells. Cell Biology International, 36, 137-145. https://doi.org/10.1042/CBI20110052

[16] Walen, K.H. (2010) Mitosis Is Not the Only Distributor of Mutated Cells: NonMitotic Endopolyploid Cells Produce Reproductive genome Reduced Cells. Cell Biology International, 34, 867-872. https://doi.org/10.1042/CBI20090502

[17] Walen, K.H. (2014) Neoplastic-Like Cell Changes of Normal Fibroblast Cells Associated with Evolutionary Conserved Maternal and Paternal Genomic Autonomous Behavior (Gonomery). Journal of Cancer Therapy, 5, 860-877.

https://doi.org/10.4236/jct.2014.59094

[18] Zasadil, L.M., Britigan, E.M.C. and Weaver, B.A. (2013) 2n or Not 2n: Aneuploidy, Polyploidy and Chromosomal Instability in Primary and Tumor Cells. Seminars in Cell \& Developmental Biology, 24, 370-379.

https://doi.org/10.1016/j.semcdb.2013.02.001

[19] Gorgoulis, V.G., Vassillou, L.-V.F., Karakaldos, P., Zacharatos, P., Kotsinas, A., Liloglou, T., et al. (2005) Activation of the DNA Damage Checkpoint and Genomic Instability in Human Precancerous Lesions. Nature, 434, 907-912. https://doi.org/10.1038/nature03485

[20] Halazonetis, T.D., Gorgoulis, V.G. and Bartec, J. (2008) An Oncogene-Induced DNA Damage Model for Cancer Development. Science, 319, 1352-1355. https://doi.org/10.1126/science.1140735

[21] Walen, K.H. (2005) Budded Karyoplasts from Multinucleated Fibroblast Cells Contain Centrosomes and Change Their Morphology to Mitotic Cells. Cell Biology International, 29, 1057-1065. https://doi.org/10.1016/j.cellbi.2005.10.016

[22] Davoli, T. and de Lange, T. (2012) Telomere-Driven Tetraploidization Occurs in Human Cells Undergoing Crisis and Promotes Transformation of Mouse Cells. Cancer Cell, 21, 765-776. https://doi.org/10.1016/j.ccr.2012.03.044

[23] Walen, K.H. (2007) Bipolar Genome Reductional Division of Human Near-Senescent, Polyploid Fibroblast Cells. Cancer Genetics and Cytogenetics, 173, 43-50. https://doi.org/10.1016/j.cancergencyto.2006.09.013

[24] Walen, K.H. (2008) Genetic Stability of Senescence Reverted Cells. Cell Cycle, 7, 1623-1629. https://doi.org/10.4161/cc.7.11.5964

[25] Walen, K.H. (2009) Spindle Apparatus Uncoupling in Endo-Tetraploid Asymmetric Division of Stem and Non-Stem Cells. Cell Cycle, 8, 3234-3237.

https://doi.org/10.4161/cc.8.19.9570

[26] DeBerardinis, R.J. and Cheng, T. (2010) Q's Next: The Diverse Function of Glutamine in Metabolism, Cell Biology and Cancer. Oncogene, 29, 313-324. https://doi.org/10.1038/onc.2009.358

[27] Freed, J.J. and Schatz, S.A. (1969) Chromosome Aberrations in Cultured Cells Deprived of Single Essential Amino Acids. Experimental Cell Research, 55, 393-409. 
https://doi.org/10.1016/0014-4827(69)90574-6

[28] Erenpreisa, J., Salmina, K., Huna, A., Kosmacek, E.A., Cragg, M.S., Ianzini, F. and Anisimov, A. (2011) Polyploid Tumor Cells Elicit Paradiploid Progeny through Depolyploidizing Divisions and Regulated Autophagic Degradation. Cell Biology International, 35, 687-695. https://doi.org/10.1042/CBI20100762

[29] Amend, S.R., Torga, G., Lin, K.-C., Kostecka, L.G., de Marzo, A., Austin, R.H. and Plenta, K.J. (2019) Polyploid Giant Cancer Cells: Unrecognized Actuators of Tumorigenesis, Metastasis, and Resistance. The Prostate, 79, 1489-1497. https://doi.org/10.1002/pros.23877

[30] Walen, K.H. (1965) Spatial Relationships in the Replication of Chromosomal DNA. Genetics, 51, 915-929. https://doi.org/10.1093/genetics/51.6.915

[31] Therman, E. and Susman, M. (1993) Human Chromosomes-Structure, Behavior, and Effects. 3rd Edition, Springer Verlag, New York. https://doi.org/10.1007/978-1-4684-0529-3

[32] Broderick, R. and Niedzwiedz, W. (2015) Sister Chromatid Decatenation: Bridging the Gaps in Our Knowledge. Cell Cycle, 14, 3040-3044.

https://doi.org/10.1080/15384101.2015.1078039

[33] Swanson, C.P. (1957) Cytology and Cytogenetics. Prentice-Hall, Englewood Cliffs.

[34] Walen, K.H. (2014) Haploidization of Human Diploid Metaphase Cells: Is This Genome Reductive Mechanism Operational in Near-Haploid Leukemia? Journal of Cancer Therapy, 5, 101-112. https://doi.org/10.4236/jct.2014.51013

[35] Gomes, E.R., Jani, S. and Gundersen, G.G. (2005) Nuclear Movement Regulated by Cdc42, MRCK, Myosin, and Actin Flow Establishes MTOC Polarization in Migrating Cells. Cell, 121, 451-463. https://doi.org/10.1016/j.cell.2005.02.022

[36] Raza, A. (2019) The First Cell: And the Human Costs of Pursuing Cancer to the Last. Hachette Book Group, New York.

[37] Kalluri, R. and Weinberg, R.A. (2009) The Basics of Epithelial-Mesenchymal Transition. Journal of Clinical Investigation, 119, 1420-1428.

https://doi.org/10.1172/JCI39104

[38] Wodarz, A. and Nathke, I. (2007) Cell Polarity in Development and Cancer. Nature Cell Biology, 9, 1016-1024. https://doi.org/10.1038/ncb433

[39] Rohnalter, V., Roth, K., Finkernagel, F., Adhikary, T., Obert, J., Dorzweiler, K., et al. (2015) A Multi-Stage Process Including, Transient Polyploidization and EMT Precedes the Emergence of Chemo Resistant Ovarian Carcinoma Cells with a Dedifferentiated and Pro-Inflammatory Secretory Phenotype. Oncotarget, 6, 40005-40025. https://doi.org/10.18632/oncotarget.5552

[40] Grell, K.G. and Ruthmann, A. (1964) Uber die Karyologie des Radiolars Aulachanta scolymantha und Feinstruktur seiner Chromosomen. Chromosoma, 15, 185-211. https://doi.org/10.1007/BF00285729

[41] Gonzalez-Robles, A., Cristobal-Ramos, A., Gonzalez-Lazaro, M., Omana-Molina, M. and Martinez-Palomo, M. (2009) Naegleria fowleri: Light and Electron Microscopy Study of Mitosis. Experimental Parasitology, 122, 212-217. https://doi.org/10.1016/j.exppara.2009.03.016

[42] Lucchetta, E.M. and Ohlstein, B. (2017) Amitosis of Polyploid Cells Regenerates Functional Stem Cells in the Drosophila Intestine. Cell Stem Cell, 20, 609-620.E6. https://doi.org/10.1016/j.stem.2017.02.012

[43] Saunders, W.S., Shuster, M., Huang, X., Gharaibe, B., Enyenihi, A.H., Petersen, J. and Gollin, S.M. (2000) Chromosomal Instability and Cytoskeleton Defects in Oral 
Cancer. Proceedings of the National Academy of Sciences of the United States of America, 97, 303-308. https://doi.org/10.1073/pnas.97.1.303

[44] Dikovskaya, D., Schiffmann, D., Newton, I.P., Oakley, A., Kroboth, K., Sansom, O., et al. (2007) Loss of APC Induces Polyploidy as a Result of a Combination of Defects in Mitosis and Apoptosis. Journal of Cell Biology, 176, 183-195. https://doi.org/10.1083/jcb.200610099

[45] Walen, K.H. (2015) Wound Healing Is a First Response in a Cancerous Pathway: Hyperplasia Developments to $4 \mathrm{n}$ Cell Cycling in Dysplasia Linked to Rb-Inactivation. Journal of Cancer Therapy, 6, 906-916. https://doi.org/10.4236/jct.2015.610099

[46] Steinbeck, R.G. (2004) Dysplasia in View of the Cell Cycle. European Journal of Histochemistry, 48, 203-211.

[47] Barrett, M.T., Pritchard, D., Palanca-Wessels, C., Anderson, J., Reid, B.J. and Rabinovitch, P.S. (2003) Molecular Phenotype of Spontaneously Arising 4N (G2-Tetraploid) Intermediates of Neoplastic Progression in Barrett's Esophagus. Cancer Research, 63, 4211-4217.

[48] Jemaa', M., Abdallah, S., Liedo, G., Perrot, G., Lesluyes, T., Teyssier, C., Roux, P., et al. (2017) Heterogeneity in Sarcoma Cell Lines Reveals Enhanced Motility of Tetraploid versus Diploid Cells. Oncotarget, 8, 16669-16689.

https://doi.org/10.18632/oncotarget.14291

[49] Cao, Y., Walen, K.H. and Schnurr, D. (1988) Coxsackievirus B-3 Selection of Virus Resistant Buffalo Green Monkey Kidney Cells and Chromosome Analysis of Parental and Resistant Cells. Archives of Virology, 101, 209-219.

https://doi.org/10.1007/BF01311002

[50] Mirzayans, R., Andrais, B., Kumar, P. and Murray, D. (2016) The Growing Complexity of Cancer Cell Response to DNA-Damaging Agents: Caspase 3 Mediates Cell Death or Survival. International Journal of Molecular Sciences, 17, 708-723. https://doi.org/10.3390/ijms17050708

[51] Bibbo, M, \& Wilburn, D. (2014) Comprehensive Cytopathology, 4th Edition, Elsevier Health, Philadephia.

[52] Wang, Q., Wu, P.C., Dong, D.Z., Ivanova, I., Chu, E., Zeliadi, S., Vesselle, H. and Wu, D.Y. (2013) Polyploidy Road to Therapy-Induced Cellular Senescence and Escape. International Journal of Cancer, 132, 1505-1515.

https://doi.org/10.1002/ijc. 27810

[53] Puig, P.-E., Guilly, M.-N., Bouchot, A., Droin, N., Cathelin, D., Bouyer, F., Favier, L., et al. (2008) Tumor Cells Can Escape DNA-Damaging Cisplatin through DNA Endoreduplication and Reversible Polyploidy. Cell Biology International, 32, 1031 1043. https://doi.org/10.1016/j.cellbi.2008.04.021

[54] Sikora, E., Mosieniak, G. and Sliwinska, M.A. (2016) Morphological and Functional Characteristic of Senescent Cancer Cells. Current Drug Targets, 17, 377-387. https://doi.org/10.2174/1389450116666151019094724

[55] Mittal, K., Donthamsetty, S., Kaur, R., Yang, C., Gupta, M.V., Reid, M.D., Choi, D.H., et al. (2017) Multinucleated Polyploidy Drives Resistance to Docetaxel Chemotherapy in Prostate Cancer. British Journal of Cancer, 116, 1186-1194. https://doi.org/10.1038/bjc.2017.78

[56] Niu, N., Zhang, J., Zhang, N., Mercado-Uribe, I., Tao, F., Han, Z., Pathak, S., Multani, A.S., et al. (2016) Linking Genomic Reorganization to Tumor Initiation via the Giant Cell Cycle. Oncogenesis, 5, Article No. e281. https://doi.org/10.1038/oncsis.2016.75

[57] Walen, K.H. (2002) The Origin of Transformed Cells: Studies of Spontaneous and 
Induced Cell Transformation in Cell Cultures from Marsupials, a Snail and Human Amniocytes. Cancer Genetics and Cytogenetics, 133, 45-54. https://doi.org/10.1016/S0165-4608(01)00572-6

[58] Walen, K.H. (2004) Spontaneous Cell Transformation: Karyoplasts Derived from Multinucleated Cells Produce New Cell Growth in Senescent, Human Epithelial Cell Cultures. In Vitro Cellular \& Developmental Biology-Animal, 40, 150-158.

[59] Walen, K.H. (2006) Human Diploid Fibroblast Cells in Senescence: Cycling through Polyploidy to Mitotic Cells. In Vitro Cellular \& Developmental Biology-Animal, 42, 216-224. https://doi.org/10.1290/0603019.1

[60] Ronnov-Jensen, L., Petersen, O.W. and Bissell, M.J. (1996) Cellular Changes Involved in Conversion of Normal to Malignant Breast: Importance of the Stromal Reaction. Physical Review Journals, 76, 69-125.

https://doi.org/10.1152/physrev.1996.76.1.69

[61] Walen, K.H. (2021) Cell Cycle Stress in Normal Human Cells: A Route to "First Cells" (with/-without Fitness Gain) and Cancer-Like Cell-Shape Changes. Seminars in Cancer Cell Biology. (In Press) https://doi.org/10.1016/j.semcancer.2020.12.023

[62] Dunnebacke, T.H. (2009) Balamuthia mandrillaris: The Multiple Nuclei of Balamuthia Amebas; Their Location, Activity and Site of Development. Experimental Parasitology, 126, 14-21. https://doi.org/10.1016/j.exppara.2009.10.012

[63] Bignold, L.P., Coghlan, B.L.D. and Jersmann, H.P.A. (2007) David von Hansemann. Contributions to Oncology, Context, Comments, and Translations. Birkhauser Verlag, Basel, Switzerland.

[64] Murga, M., Jaco, I., Fan, Y., Soria, R., Martinez-Pastor, B., Cuadrado, M., et al. (2007) Global Chromatin Compaction Limits the Strength of the DNA Damage Response. Journal of Cell Biology, 178, 1101-1108. https://doi.org/10.1083/jcb.200704140

[65] Walen, K.H. (2013) Normal Human Cells Acquiring Proliferative Advantage to Hyperplasia-Like Growth-Morphology: Aberrant Progeny Cells Associated with Endopolyploid and Haploid Divisions. Cancer and Clinical Oncology, 2, 19-33. https://doi.org/10.5539/cco.v2n2p19

[66] Walen, K.H. (2011) Normal Human Cell Conversion to 3-D Cancer-Like Growth: Genome Damage, Endopolyploidy, Senescence Escape, and Cell Polarity Change/ Loss. Journal of Cancer Therapy, 2, 181-189. https://doi.org/10.4236/jct.2011.22023

[67] Gisselsson, D. and Egnell, R. (2017) Cancer-An Insurgence of Clones. Trends in Cancer, 3, 73-75. https://doi.org/10.1016/j.trecan.2016.11.010

[68] Edgar, B.A. and Orr-Weaver, T.I. (2001) Endoreplication Cell Cycles: More for Less. Cell, 105, 297-306. https://doi.org/10.1016/S0092-8674(01)00334-8

[69] Lee, H.O., Davidson, J.M. and Duronio, R.J. (2009) Endoreplication: Polyploidy with a Purpose. Genes \& Development, 23, 2461-2477. https://doi.org/10.1101/gad.1829209

[70] Fox, D.T. and Duronio, R.J. (2013) Endoreplication and Polyploidy: Insight into Development and Disease. Development, 140, 3-12.

https://doi.org/10.1242/dev.080531

[71] Ravid, K., Lu, J., Zimmet, J.M. and Jones, M.R. (2002) Roads to Polyploidy: The Megakaryocyte Example. Journal of Cellular Physiology, 190, 7-20. https://doi.org/10.1002/jcp.10035

[72] Erenpreisa, J., Kalejs, M. and Cragg, M.S. (2005) Mitotic Catastrophe and Endomitosis in Tumor Cells: An Evolutionary Key to a Molecular Solution. Cell Biology International, 29, 1012-1018. https://doi.org/10.1016/j.cellbi.2005.10.005 
[73] Salmina, K., Bojko, A., Inashkina, I., Staniak, K., Dudkowska, M., Podlesniy, P., et al. (2020) "Mitotic Slippage" and Extranuclear DNA in Cancer Chemoresistance: A Focus on Telomeres. International Journal of Molecular Sciences, 21, Article No. 2779. https://doi.org/10.3390/ijms21082779

[74] Brito, D. and Rieder, C.L. (2006) Mitotic Slippage in Humans Occurs via Cyclin B Destruction in the Presence of an Active Checkpoint. Current Biology, 16, 1194 2000. https://doi.org/10.1016/j.cub.2006.04.043

[75] Gisselsson, D., Petterson, L., Hoglund, M., Heldenbla, M., Gorunova, L., et al., (2000) Chromosomal Breakage-Fusion-Bridge Events Cause Genetic Intratumor Heterogeneity. Proceedings of the National Academy of Sciences of the United States of America, 97, 5357-5362. https://doi.org/10.1073/pnas.090013497

[76] Margolis, R.L., Lohez, O.D. and Andreassen, P.R. (2003) G1 Tetraploidy Checkpoint and Suppression of Tumorigenesis. Journal of Cellular Biochemistry, 88, 673-688. https://doi.org/10.1002/jcb.10411

[77] Schwarzacher, H.G. and Schnedl, W. (1966) Position of Labelled Chromatids in Diplochromo-Somes of Endo-Reduplicated Cells after Uptake of Tritiated Thymidine. Nature, 209, 107-108. https://doi.org/10.1038/209107a0

[78] Ganem, N.J. and Pellman, D. (2012) Linking Abnormal Mitosis to the Acquisition of DNA Damage. Journal of Cell Biology, 199, 871-880.

https://doi.org/10.1083/jcb.201210040

[79] Ganem, N.J., Storchova, Z. and Pellman, D. (2007) Tetraploidy, Aneuploidy and Cancer. Current Opinion in Genetics \& Development, 17, 157-162. https://doi.org/10.1016/j.gde.2007.02.011

[80] Blagosklonny, M.V. (2007) Cancer Stem Cell and Cancer Stemloids. Cancer Biology \& Therapy, 6, 1684-1690. https://doi.org/10.4161/cbt.6.11.5167

[81] Heim, S. and Mitelman, F. (1995) Cancer Cytogenetics: Chromosomal and Molecular Genetic Aberrations of Tumor Cells. 2nd Edition, Wiley-Liss, Inc., New York.

[82] Wilson, T., Artl, M.F., Park, S.H., Rajendran, S., Paulsen, M., Ljungman, M. and Glover, T.W. (2015) Large Transcription Units Unify Copy Number Variant and Common Fragile Sites Arising under Replication Stress. Genome Research, 25, 189200. https://doi.org/10.1101/gr.177121.114

[83] Bayani, J., Paderova, J., Murphy, J., Rosen, B., Zielenska, M. and Squire, J.A. (2008) Distinct Patterns of Structural and Numerical Chromosomal Instability Characterize Sporadic Ovarian Cancer. Neoplasia, 10, 1057-1065.

https://doi.org/10.1593/neo.08584

[84] Gondek, L.P., Tiu, R., O’Keefe, C.L., Sekeres, M.A., Theil, K.S. and Maciejewski, P. (2013) Chromosomal Lesions and Uniparental Disomy Detected by SNP Arrays in MDS, MDS/MPD and MDS-Derived AML. Blood, 111, 1534-1542. https://doi.org/10.1182/blood-2007-05-092304

[85] Liu, J. (2019) The "life code": A Theory That Unifies the Human Life Cycle and the Origin of Human Tumors. Seminars in Cancer Biology, 60, 380-397. https://doi.org/10.1016/j.semcancer.2019.09.005

[86] Deng, G., Lu, Y., Zlotnikov, G., Thor, A.D. and Smith, H.S. (1996) Loss of Heterozygosity in Normal Tissue Adjacent to Breast Carcinomas. Science, 274, 2057-2059. https://doi.org/10.1126/science.274.5295.2057

[87] Anatskaya, O.V., Vinogradov, A.E., Vainshelbaum, N.M., Giuliani, A. and Erenpreisa, J. (2020) Phylostratic Shift to Whole-Genome Duplications in Normal Mammalian Tissues towards Unicellularity Is Driven by Developmental Bivalent Genes 
and Reveals a Link to Cancer. International Journal of Molecular Sciences, 21, 87598779. https://doi.org/10.3390/ijms21228759

[88] Erenpreisa, J., Salmina, K., Anatskaya, O. and Cragg, M.S. (2021) Paradoxes of Cancer: Survival on the Brink. Seminars in Cancer Biology. (In Press)

https://doi.org/10.1016/j.semcancer.2020.12.009

[89] Harnden, D.G. and Klinger, H.P. (Eds.) (1985) An International System for Human Cytogenetic Nomenclature (ISCN). Karger Publishing Co., New York.

[90] Witte, J.S. (2009) Prostate Cancer Genomics: Towards a New Understanding. Nature Review Genetics, 10, 77-82. https://doi.org/10.1038/nrg2507

[91] Saldivar, J.C., Miuma, S., Bene, J., Hosseini, S.A., Shibata, H., et al. (2012) Initiation of Genome Instability and Preneoplastic Processes through Loss of Fhit Expression. PLoS Genetics, 8, e1003077. https://doi.org/10.1371/journal.pgen.1003077

[92] Bene, J. (2012) The Role of the Common Fragile Site Gene Product, Fhit, in Protection from DNA Damage. Senior Honors Research Thesis, The Ohio State University, Columbus.

[93] Durkin, S.G., Ragland, R.L., Artl, M.F., Mulle, J.G., Warren, S.T. and Glover, T.W. (2008) Replication Stress Induces Tumor-Like Microdeletions in FHIT/FRA3B. Proceedings of the National Academy of Sciences of the United States of America, 105, 246-251. https://doi.org/10.1073/pnas.0708097105

[94] Jackson, S.P. and Helleday, T. (2016) Drugging DNA Repair. Science, 352, 1178-1179. https://doi.org/10.1126/science.aab0958

[95] Khamsi, R. (2020) Computing Cancer's Weak Spots. An Algorithm to Unmask Tumors' Molecular Linchpins Is Tested in Patients. Science, 368, 1174-1177. https://doi.org/10.1126/science.368.6496.1174

[96] Couzin-Frankel, J. (2020) CRISPR Takes on Cancer. Science, 367, 616. https://doi.org/10.1126/science.367.6478.616 


\section{Glossary}

$4 \mathrm{~N}-\mathrm{SDS}=4 \mathrm{n}$-skewed division system,

SMGs = significantly mutated genes,

$\mathrm{CNV} / \mathrm{As}=$ copy number variation/alteration,

HSRs = homogeneously staining regions,

DMs $=$ double minutes,

$\mathrm{MT}=$ mutation theory.

\section{Literature List of Cancer Evolution}

1) Genome damage response: [10] [11] [19]-[27] [30] [45] [50] [78] [79].

2) Fragile site associated mutations [4] [5] [84] [91] [92] [93].

3) Mitotic slippage process [73] [74] [75].

4) Polyploid reductive genome division [28] [29] [34] [39] [46] [47] [48] [52] [53] [54] [55] [56] [85].

5) First Cells, two types, fitness gained and not [12] [36] [61] [62] [83].

6) Extended growth of 4n-derived fitness gained First Cells [65] [66] [67].

7) Amitotic-mitosis [41] [42] [43] [44].

8) Therapy [14] [94] [95] [96].

9) Literature in opposition [1] [2] [3] [7] [14] [37] [71]. 